\title{
Radiolucent esophageal foreign body presenting as a middle mediastinal mass and tracheoesophageal fistula
}

\author{
Joseph M. Baylan, MD, ${ }^{a}$ and Kelly D. Mattix, $\mathrm{MD}^{\mathrm{b}}$
}

Esophageal foreign-body (FB) ingestion occurs in more than 100,000 cases per year. ${ }^{1}$ When it is recognized or suspected early, intervention is possible and is associated with limited morbidity and mortality. FB ingestion in adults is associated with a classic presentation, but the presentation may be obscure in the pediatric population. About 50\% of patients have atypical symptoms or even no symptoms at all. ${ }^{2}$ Diagnosis is therefore often aided by radiographic imaging.

An 18-month-old boy was seen for a history of 4 to 6 months of stridor and progressive dysphagia with solids

From the Scott and White Memorial Hospital, ${ }^{\mathrm{a}}$ Texas A\&M Health Science Center, Temple, Tex; and the Department of Pediatric Surgery, ${ }^{\mathrm{b}}$ McLane Children's Hospital, Temple, Tex.

Disclosures: Authors have nothing to disclose with regard to commercial support. Received for publication Oct 9, 2013; revisions received March 17, 2014; accepted for publication April 14, 2014; available ahead of print June 11, 2014. Address for reprints: Kelly D. Mattix, MD, 2401 S 31st St, Temple, TX 76508

(E-mail: kdmattix@gmail.com).

J Thorac Cardiovasc Surg 2014;148:2420-1

$0022-5223 / \$ 36.00$

Copyright (c) 2014 by The American Association for Thoracic Surgery

http://dx.doi.org/10.1016/j.jtcvs.2014.04.030


FIGURE 1. Axial and coronal chest computed tomography displaying a middle mediastinal mass (within green circle) with tracheal deviation.

FIGURE 3. Postresection photograph of the foreign body that caused the fistula, an almost fully intact leaf. 
(Figure 1). Laboratory values, tumor markers ( $\alpha$-fetoprotein and $\beta$-human chorionic gonadotropin), and inflammatory markers (erythrocyte sedimentation rate and C-reactive protein) were within normal limits. Esophagography revealed a tracheoesophageal fistula (Figure 2).

The patient was taken to the operating room. Rigid bronchoscopy demonstrated tracheal narrowing, with inflammation and narrowing at the takeoff of the left main stem bronchus. The posterior aspect of the trachea showed no evidence of a fistula. Flexible esophagoscopy revealed erythematous changes in the distal esophagus, consistent with reflux, but again no fistula. A right thoracotomy was performed and a mass was noted; this mass was carefully dissected and found to be an esophageal diverticulum. Sharp dissection yielded visualization of the FB, an almost fully intact leaf (Figure 3). A 2-mm defect in the posterior trachea was noted and repaired primarily.
The patient's postoperative course was uneventful. Repeated esophagography showed a mild esophageal stricture, which responded to dilation. The patient is now free of symptoms.

The diagnosis of a retained FB is common, especially in the pediatric population. Any delay in diagnosis can lead to complications, such as the tracheoesophageal fistula seen in our patient. In treating children with an atypical presentation and a constellation of symptoms, a retained esophageal FB should therefore be included in the differential diagnosis.

\section{References}

1. Kay M, Wyllie R. Pediatric foreign bodies and their management. Curr Gastroenterol Rep. 2005; 7:212-8.

2. Miller RS, Willging JP, Rutter MJ, Rookkapan K. Chronic esophageal foreign bodies in pediatric patients: a retrospective review. Int J Pediatr Otorhinolaryngol. 2004;68:265-72. 